ScIDice

\section{Prevalence Of Canal Variations In Mandibular 1st Molar In South Indian Population And Association With Age And Gender}

Research Article

Vaishnavi Devi. B ${ }^{1}$, S. Delphine Priscilla Antony ${ }^{2 *}$

${ }^{1}$ Saveetha Dental College and Hospital, Saveetha Institute of Medical and Technical Science, Saveetha University, India.

${ }^{2}$ Senior Lecturer, Department of Conservative Dentistry and Endodontics, Saveetha Dental College and Hospital, Saveetha Institute Of Medical and Technical Science, Saveetha University, India.

\title{
Abstract
}

Background: Mandibular first molars are amongst the most common teeth requiring endodontic treatment due to their early emergence in the oral cavity and subsequent caries. Proper knowledge and understanding of the root canal morphology and anatomy of mandibular first molars, will help the clinician in developing a proper and standard treatment protocol by predicting possible variations that potentially challenge the treatment outcome.

Aim: The main objective of the present study was to know the prevalence of canal variations in mandibular 1st molar among the South Indian population and its association with age and gender. Materials and method - All the patients who reported during June 2019 to March 2020 for mandibular 1st molar endodontic therapy were chosen for the study. Information was collected from the dental hospital record system and the resulting data was tabulated in excel and imported to SPSS for correlation and association. Results: Within the limits of the study the results obtained are: prevalence of canal variations is $7.6 \%$ and $2.2 \%$ in single and multi visit root canal treatment respectively with an higher incidence among the male patients and it is primarily seen in the age group of 21 to 40 years.

Conclusion: This knowledge about the canal variations in the South Indian population will be helpful to the clinician to look for any unusual anatomy while performing endodontic therapy which will prevent any unwanted procedural errors. It necessitates the careful negotiation and cleaning of all accessible canal spaces.

Keywords: Mandibular Molars; Canal Variation; C Shaped Canal; Anatomy; Endodontic Therapy; Morphology.

\section{Introduction}

Success of an endodontic therapy depends mainly on adequate debridement and removal of the necrotic pulpal tissue followed by obturation of the root canal [26]. Knowledge of root canal anatomy, its configurations and possible variations is important for success of the treatment $[17,1]$. Complex root canal morphology and the presence of an untreated canal is always a clinical challenge which can often compromise the outcome of the treatment $[23,18]$. The efficiency of the diagnostic aids also plays an important role in the success of the treatment [14]. It is important for the clinicians to use all the required armamentarium to locate and treat the entire root canal system [34, 23]. Methods used to study complex root canal morphology include intraoral radiographs, tooth sectioning, clinical observation, direct microscope and computed tomography [43]. All of these methods help us to observe and understand the presence of root canal morphology and its abnormal configurations.

Each root canal begins as a channel of the canal orifice and is generally present apical to the cervical line [38]. Usually the roots of primary teeth have single large canals, with age there would be increased deposition of secondary dentine. Eventually resulting in the formation of seperations, which causes substantial modification of the root canal system sequelling to development of separate canals [8]. The modification of a simple root canal into a complex form occurs mostly in roots which have external grooves. The mandibular first molar is typically presented with two roots, a mesial root and straight, more rounded distal root with three canals [6]. The distal surfaces of these roots have a parabolic angle which makes the wall very thin. Mostly all the root

*Corresponding Author

S. Delphine Priscilla Antony,

Senior Lecturer, Department of Conservative Dentistry and Endodontics, Saveetha Dental College and Hospital, Saveetha Institute Of Medical and Technical Science, Saveetha University, India.

E-mail: delphine.sdc@saveetha.com

Received: November 09, 2020

Accepted: November 22, 2020

Published: November 30, 2020

Citation: Vaishnavi Devi. B, S. Delphine Priscilla Antony. Prevalence Of Canal Variations In Mandibular 1st Molar In South Indian Population And Association With Age And Gender. Int J Dentistry Oral Sci. 2020;S10:02:0023:125-130. doi: http://dx.doi.org/10.19070/2377-8075-SI02-0100023

Copyright: S. Delphine Priscilla Antony ${ }^{\circ} 2020$. This is an open-access article distributed under the terms of the Creative Commons Attribution License, which permits unrestricted use, distribution and reproduction in any medium, provided the original author and source are credited. 
canals are curved in a labio-lingual direction. These curvatures create obstacles during biomechanical preparation because they are not usually visible on a periapical radiograph $[42,29]$.

The root canal is complex and canals can branch, divide and rejoin [12]. However due to familial, ethnic and gender differences in a population, a wide range of anatomic and morphological variations are encountered [37]. Most of the root canal variations are seen in mandibular molars due to their divergent root structures [21]. Sometimes, middle mesial canal can be found in the groove between the mesiolingual and mesiobuccal canals with its incidence ranging between $1 \%$ to $13.3 \%$ [36, 25]. C-shaped canals in mandibular molars is one of the most common anatomic variations of the root canal system and is named after its cross sectional morphology [19]. While most C-shaped canals occur in the mandibular second molar, they have also been reported in the mandibular first molar, and the mandibular first premolar. The occurrence of these variations in mandibular first molars is less than $3 \%$ in African populations, $4.2 \%$ in Caucasians, less than $5 \%$ in Asian populations and higher than 5\% in populations with Mongolian traits [13]. According to a study of Reuben et.al, the prevalence of root canal variations in Indian population shows that there is an incidence of $4.84 \%$ with the majority having normal root canal morphology and no statistical differences among the female and male patients [31].

The anatomy of the root canal system varies greatly in different populations and among the different individuals within the same population, thus it is important to be aware of complexities in tooth anatomy among racial groups because this understanding will help clinician in providing better treatment [44]. Bayirli in his study, concluded that gender and ethnicity plays a role in determining the root canal anatomy and that both should be considered during the pre- operative stage of root canal therapy [34]. Clinical determination of root canal anatomy is challenging at best $[11,39,35,22]$. All of these factors are important to be known and considered by dentists to suggest an appropriate measure to prevent any further complications and long term damage to the oral tissues $[32,30,15]$. Although the pulpal anatomy of mandibular molars has been extensively studied, information about canal variations is limited. The main aim of this study is to know the prevalence of canal variations in mandibular 1st molar in the South Indian population and its association with age and gender.

\section{Materials And Methods}

\section{Study setting}

This retrospective cross sectional study is about knowing the prevalence of canal variations in mandibular 1st molar endodontic therapy. A randomised sample of healthy adults who had undergone root canal therapy in the mandibular 1 st molar were chosen for the study. The study took place in a hospital setting within the university. The retrospective data was being ethically approved(ethical approval number: SDC/SIHEC/2020/DIASDATA/0619-0320) and the number of people involved in the study includes 3 members - Guide, researcher, reviewing expert.

\section{Sampling}

All the cases reported for mandibular 1st molar endodontic ther- apy from the month of june 2019 to march 2020 was required for the study. The records of all patient data were obtained from the dental hospital record system from initial to last and were arranged in chronological order. A total of 86000 patient records were reviewed and analysed for the study. All the data were properly verified and cross verified by another examiner. Sampling bias was minimised by simple random sampling. The sample size includes 1239 multi visit RCT patients and 403 single visit RCT patients.

\section{Data analysis}

The collected data includes both single visit and multi visit, 1st mandibular molar RCT details. Gross incomplete data was excluded as it affects the study. Excel tabulation of all the verified data along with SPSS importing was done. Data was imported to the SPSS software for the statistical tests. The data was assessed by being subjected to descriptive analysis with the help of frequencies, percentage and analysed by running descriptive statistics in the form of crosstabs. Independent variables in the study include ethnicity, age and gender whereas dependent variables include canal variations. Non parametric Chi square statistical test was done and the results were correlated and associated.

\section{Results And Discussion}

The study evaluated the prevalence of canal variations in mandibular 1st molar among the patients visiting Saveetha Dental College. A total of 1642 patients' mandibular 1st molar root canal treatment records were included in this study. The statistical software SPSS was used for the descriptive and inferential analysis. Results on categorical measurement were presented in percentage $(\%)$. Level of significance was predetermined at the probability value of $\mathrm{P}=0.05$ and any value $\leq 0.05$ was considered to be statistically significant.

Age prevalence in root canal treated patients infer that below the age of 20 years $3(0.74 \%)$ in single visit and 9 patients $(0.73 \%)$ have reported with the root canal variations. In the age group of 21 to 40 years 17 patients $(4.22 \%)$ in single visit RCT and 13 $(1.05 \%)$ patients in multi visit RCT have been reported. 7 patients $(1.74 \%)$ in single visit RCT and 6 patients $(0.48 \%)$ in multi visit RCT in the age group of 41 to 60 years have reported. Above the age group of 60 years, 3 patients $(0.74 \%)$ in single visit and no patients in multi visit RCT have reported with canal variations. The remaining patient population shows normal root canal morphology. It shows that 21 to 40 years show more prevalence of canal variations in mandibular 1st molars in both single and multi visit RCT (Figure 1, 2). P value is $=0.001$ and hence it is statistically significant.

Gender prevalence in this study shows that among 403 patients who had undergone endodontic therapy in a single visit RCT, 19 male patients have been reported with canal variations and $11 \mathrm{fe}-$ male patients have reported (Figure 3). Similarly, 1239 patients reported for multi visit RCT, in which 23 male patients have reported with root canal variations and 5 female patients have reported with the rest of the patients having normal root canal (Figure 4). There is an increased prevalence of canal variations in male patients in both single and multi visit RCT. $P$ value is $=0.002$ and hence it is statistically significant. 
Figure 1. Bar graph showing the prevalence of canal variations in single visit RCT among different age groups of patients. $x$ axis represents age group and $y$ axis represents the number of patients. There is a significant higher incidence in the age group of 21 to 40 years among these patients. $(p)=0.001$ statistically significant.

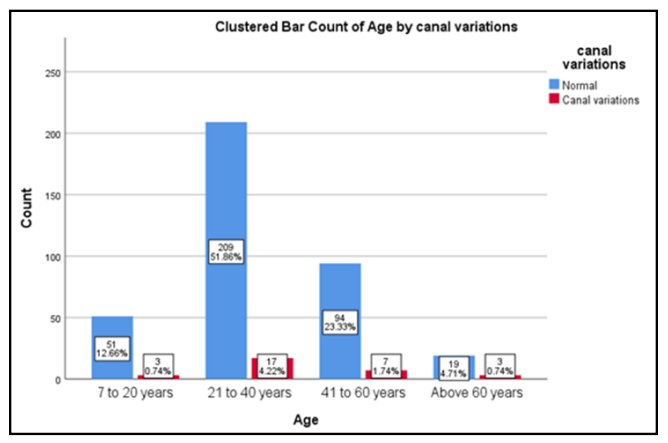

Figure 2. Bar graph showing the prevalence of canal variations in multi visit RCT among different age groups. $x$ axis represents age group and $y$ axis represents the number of patients. There is a significant higher incidence in the age group of 21 to 40 years among these patients. $(p)=0.001$ statistically significant.

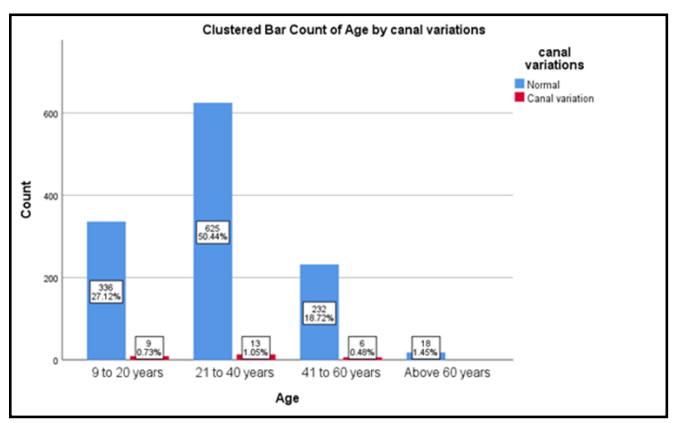

Figure 3. Bar graph showing the association between canal variations in single visit RCT and gender. $\mathrm{x}$ axis represents gender of the patient and $y$ axis represents the number of patients. There is a significant higher incidence of male patients reported with canal variations than the female patients. $(p)=0.004$ statistically significant.

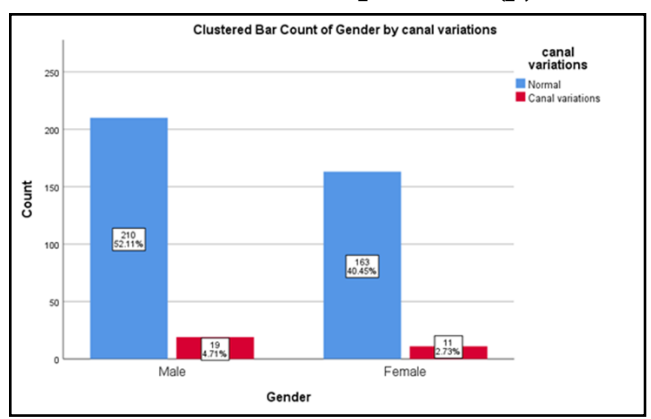

Figure 4. Bar graph showing the association between canal variations in multi visit RCT and gender. $\mathrm{x}$ axis represents gender of the patient and $y$ axis represents the number of patients. There is a significant higher incidence of male patients reported with canal variations than the female patients. $(p)=0.002$ statistically significant.

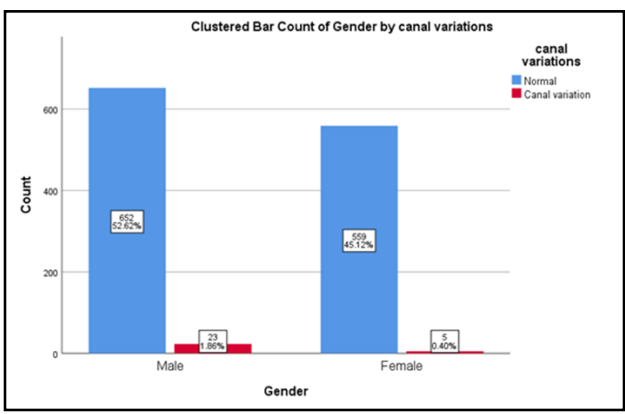

Root canal variation prevalence among the mandibular 1 st molar reported patients shows that 31 patients $(7.6 \%)$ out of 403 patients in single visit RCT and 28 patients $(2.2 \%)$ in multi visit RCT have canal variations and the remaining have normal root canal anatomy (Figure 5,6). P value is $=0.001$ and hence it is statistically significant. The data shows that there is a higher incidence of canal variations in single visit when compared to multi visit RCT. The probability value is $=0.001$ for the study and hence the study was statistically significant.

Dental caries is the most common cause for the loss of tooth in a clinical situation, hence the final option in saving the tooth is endodontic therapy [27]. Anatomy and morphology knowledge 
Figure 5. Bar graph showing the prevalence of canal variations in single visit RCT. $x$ axis represents the prevalence of canal variations and $y$ axis represents the number of patients. There is a significant incidence of canal variations among the patients reported. $(p)=0.001$ statistically significant.

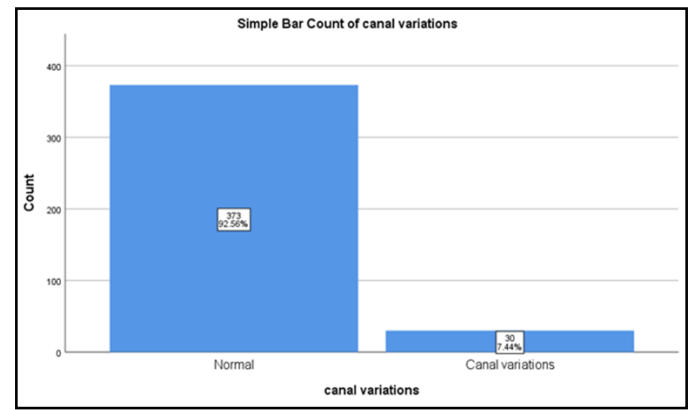

Figure 6. Bar graph showing the prevalence of canal variations in multi visit RCT. $x$ represents the prevalence of canal variations and $y$ axis represents the number of patients. There is a significant incidence of canal variations among the patients reported. $(p)=0.001$ statistically significant.

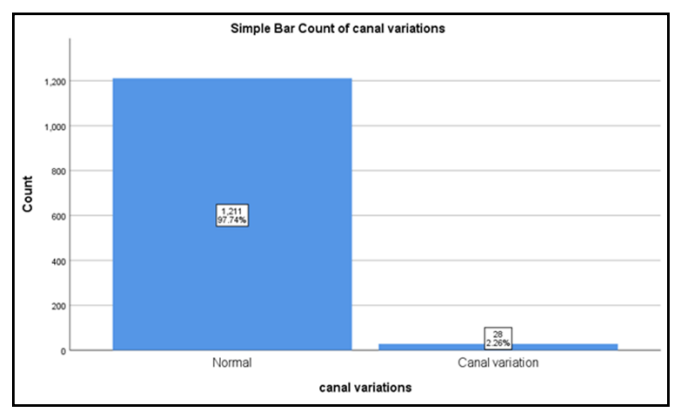

of the root canal has an important role in endodontic treatments [3]. Gao et.al have reported variations in the root canals along with the location of the canals. These include the presence of additional canals or any anatomical variations [5]. If the presence of any variation is suspected through a variety of preoperative intraoral radiographs at different angles, then adequate cavity access will help in the correct localization of root canal orifices. Sometimes, it may be difficult to visualize the variations radiographically, hence the use of an electronic apex locator and direct microscope will be helpful in detection [41].

The pattern of age distribution in the prevalence of canal variations showed that people of all groups have canal variations however peak incidence was observed among the age group of 21 to 40 years (Fig 1,2$)$ ( $p=0.001$, statistically significant). This finding is in concordance with a study, $32.1 \%$ canal variations reported in 21 to 40 years [24] and similarly in a study held among chinese population, patients aged 20 to 30 years showed a higher prevalence of additional root canals [46] and shows that this prevalence does not vary with gender and tooth position. Younger patients have a significantly higher incidence of canal variations. Continued deposition of secondary dentin [20] within the root as the age progresses will divide it into separate canals producing changes in the number and size of the root canals, as well as many small connecting branches between the facial and lingual aspects of the canals [7].

Morphological variations in root canal anatomy due to gender and genetic differences have been reported earlier in few studies (10). In our study, there was a male preponderance in the prevalence of root canal variations (Fig 3, 4) ( $p=0.002$, statistically significant). This finding is in concordance with the previous study held among the Iran population, shows that the male patients show more deviation in the root canal anatomy $[4,10]$.
In our study the prevalence of canal variation in single and multi visit RCT is $7.6 \%$ and $2.2 \%$ respectively (Fig 5,6) ( $\mathrm{p}=0.001$, statistically significant). Additional canals were found in $34.39 \%$ of the mesiobuccal roots, $0.30 \%$ of the mid buccal roots, $0.30 \%$ of the distobuccal roots, and $1.82 \%$ of the palatal roots. There is an increased tendency to locate the middle mesial canal in second molars $(60 \%)$ versus first molars (37.5\%) [33]. According to a study on Chinese population using CBCT on permanent mandibular first molars concluded that most mesial roots had more complex canal morphologies when compared to the distal roots [45]. A recent study evaluating root anatomy of permanent mandibular molars shows that there was high prevalence of C-shaped root canals in the Korean population [16]. It occurs due to the failure of the Hertwig's epithelial root sheath to fuse to the facial and lingual side. All these above studies show that the configuration of the root canal system varies with different frequencies in different populations. Several possible reasons may account for these differences, such as ethnicity of the populations, sample size, and the method used to study the canal variations.

Cohenhca reported that these canal variations pave way for the infectious microorganisms to enter into the root canal system even if the main canals were well obturated [2]. These canal variations cannot be obturated using gutta-percha instead can be made patent using root canal irrigants as it prevents any reinfection of the root canal system through periodontal ligament space and also reduces the postoperative pain $[28,40,9]$.

There is a geographic limitation to the study as it predominantly covers the South Indian population and it is also an unicentered study. This can be modified by performing longitudinal and periodic studies to evaluate the prevalence of canal variations. In the future, a larger population with different ethnicity can be included 
to provide better results. This study gives valuable information to dental practitioners in proposing strategies for the management of canal variations. It will be helpful in creating awareness by knowing the prevalence among different gender and age groups.

\section{Conclusion}

Within the limits of the current study the prevalence of canal variations in both single and multi visit RCT of the mandibular 1 st molar is known and it was more common in the male population among the age group of 21 to 40 years. Thorough knowledge of root morphology and its associated root canal anatomy with possible variations forms the prime basis for the success of any endodontic therapy. The importance of accurately determining the presence of variations in root canals is reflected in the increased failure rate that occurs when additional canals are missed during root canal therapy.

\section{References}

[1]. Chourasia HR, Meshram GK, Warhadpande M, Dakshindas D. Root canal morphology of mandibular first permanent molars in an Indian population. Int J Dent. 2012;2012:745152. Pubmed PMID: 22287965.

[2]. Cohenca N. Disinfection of Root Canal Systems. N. Cohenca, Ed. 2014.

[3]. Fan B, Cheung GS, Fan M, Gutmann JL, Fan W. C-shaped canal system in mandibular second molars: Part II--Radiographic features. J Endod. 2004 Dec;30(12):904-8. Pubmed PMID: 15564875.

[4]. Faramarzi F, Vossoghi M, Shokri A, Shams B, Vossoghi M, Khoshbin E. Cone beam computed tomography study of root and canal morphology of maxillary first molar in an Iranian population. Avicenna Journal of Dental Research. 2015 Jun 20;7(1):5-.

[5]. Gao Y, Fan B, Cheung GS, Gutmann JL, Fan M. C-shaped canal system in mandibular second molars part IV: 3-D morphological analysis and transverse measurement. J Endod. 2006 Nov;32(11):1062-5. Pubmed PMID: 17055907.

[6]. Goel NK, Gill KS, Taneja JR. Study of root canals configuration in mandibular first permanent molar. J Indian Soc Pedod Prev Dent. 1991 Mar;8(1):124. Pubmed PMID: 2056340

[7]. Goerig AC, Camp JH. Root canal treatment in primary teeth: a review. Pediatr Dent. 1983 Mar;5(1):33-7. Pubmed PMID: 6574437.

[8]. Günday M, Sazak H, Garip Y. A comparative study of three different root canal curvature measurement techniques and measuring the canal access angle in curved canals. J Endod. 2005 Nov;31(11):796-8. Pubmed PMID: 16249721

[9]. Haapasalo M, Udnæs T, Endal U. Persistent, recurrent, and acquired infection of the root canal system post-treatment. Endodontic topics. 2003 Nov;6(1):29-56

[10]. Hosseinpour S, Kharazifard MJ, Khayat A, Naseri M. Root Canal Morphology of Permanent Mandibular Premolars in Iranian Population: A Systematic Review. Iran Endod J. 2016 Summer;11(3):150-6. Pubmed PMID: 27471522.

[11]. Hussainy SN, Nasim I, Thomas T, Ranjan M. Clinical performance of resinmodified glass ionomer cement, flowable composite, and polyacid-modified resin composite in noncarious cervical lesions: One-year follow-up. J Conserv Dent. 2018 Sep-Oct;21(5):510-515. Pubmed PMID: 30294112.

[12]. Jacobsen EL, Dick K, Bodell R. Mandibular first molars with multiple mesial canals. J Endod. 1994 Dec;20(12):610-3. Pubmed PMID: 7759990

[13]. Jafarzadeh $\mathrm{H}$, Wu YN. The C-shaped root canal configuration: a review. J Endod. 2007 May;33(5):517-23. Pubmed PMID: 17437864

[14]. Janani K, Palanivelu A, Sandhya R. Diagnostic accuracy of dental pulse oximeter with customized sensor holder, thermal test and electric pulp test for the evaluation of pulp vitality: an in vivo study. Brazilian Dental Science. 2020 Jan 31;23(1):8-p.

[15]. Jose J, Subbaiyan H. Different treatment modalities followed by dental practitioners for ellis class 2 fracture-A questionnaire-based survey. The Open Dentistry Journal. 2020 Feb 18;14(1)

[16]. Kim Y, Lee SJ, Woo J. Morphology of maxillary first and second molars analyzed by cone-beam computed tomography in a korean population: variations in the number of roots and canals and the incidence of fusion. J Endod. 2012 Aug;38(8):1063-8. Pubmed PMID: 22794206

[17]. Kumar D, Antony SD. Calcified canal and negotiation-A review. Research
Journal of Pharmacy and Technology. 2018 Aug 1;11(8):3727-30.

[18]. Manohar MP, Sharma S. A survey of the knowledge, attitude, and awareness about the principal choice of intracanal medicaments among the general dental practitioners and nonendodontic specialists. Indian J Dent Res. 2018 Nov-Dec;29(6):716-720. Pubmed PMID: 30588997.

[19]. Martins JN, Mata A, Marques D, Anderson C, Caramês J. Prevalence and Characteristics of the Maxillary C-shaped Molar. J Endod. 2016 Mar;42(3):383-9. Pubmed PMID: 26806590.

[20]. Nandakumar M, Nasim I. Comparative evaluation of grape seed and cranberry extracts in preventing enamel erosion: An optical emission spectrometric analysis. J Conserv Dent. 2018 Sep-Oct;21(5):516-520. Pubmed PMID: 30294113.

[21]. Ng YL, Aung TH, Alavi A, Gulabivala K. Root and canal morphology of Burmese maxillary molars. Int Endod J. 2001 Dec;34(8):620-30. Pubmed PMID: 11762499.

[22]. Noor SS. Chlorhexidine: Its properties and effects. Research Journal of Pharmacy and Technology. 2016 Oct 1;9(10):1755.

[23]. de Pablo OV, Estevez R, Péix Sánchez M, Heilborn C, Cohenca N. Root anatomy and canal configuration of the permanent mandibular first molar: a systematic review. J Endod. 2010 Dec;36(12):1919-31. Pubmed PMID: 21092807.

[24]. Park JB, Kim N, Park S, Ko Y. Evaluation of number of roots and root anatomy of permanent mandibular third molars in a Korean population, using cone-beam computed tomography. Eur J Dent. 2013 Jul;7(3):296-301. Pubmed PMID: 24926209.

[25]. Peiris R, Takahashi M, Sasaki K, Kanazawa E. Root and canal morphology of permanent mandibular molars in a Sri Lankan population. Odontology. 2007 Jul;95(1):16-23. Pubmed PMID: 17660977.

[26]. Rahimi S, Shahi S, Lotfi M, Zand V, Abdolrahimi M, Es'haghi R. Root canal configuration and the prevalence of $\mathrm{C}$-shaped canals in mandibular second molars in an Iranian population. J Oral Sci. 2008 Mar;50(1):9-13. Pubmed PMID: 18403877.

[27]. Rajendran R, Kunjusankaran RN, Sandhya R, Anilkumar A, Santhosh R, Patil SR. Comparative evaluation of remineralizing potential of a paste containing bioactive glass and a topical cream containing casein phosphopeptide-amorphous calcium phosphate: An in vitro study. Pesquisa brasileira em odontopediatria e clinica integrada. 2019;19.

[28]. Ramamoorthi S, Nivedhitha MS, Divyanand MJ. Comparative evaluation of postoperative pain after using endodontic needle and EndoActivator during root canal irrigation: A randomised controlled trial. Aust Endod J. 2015 Aug;41(2):78-87. Pubmed PMID: 25195661.

[29]. Ramanathan S, Solete P. Cone-beam Computed Tomography Evaluation of Root Canal Preparation using Various Rotary Instruments: An in vitro Study. J Contemp Dent Pract. 2015 Nov 1;16(11):869-72. Pubmed PMID: 26718293.

[30]. Ravinthar K. Recent advancements in laminates and veneers in dentistry. Research Journal of Pharmacy and Technology. 2018 Feb 1;11(2):785-7.

[31]. Reuben J, Velmurugan N, Kandaswamy D. The evaluation of root canal morphology of the mandibular first molar in an Indian population using spiral computed tomography scan: an in vitro study. J Endod. 2008 Feb;34(2):212-5. Pubmed PMID: 18215685.

[32]. Rajakeerthi R, Nivedhitha MS. Natural Product as the Storage medium for an avulsed tooth-A Systematic Review. Cumhuriyet Dental Journal. 2019;22(2):249-56.

[33]. Rwenyonyi CM, Kutesa A, Muwazi LM, Buwembo W. Root and canal morphology of mandibular first and second permanent molar teeth in a Ugandan population. Odontology. 2009 Jul;97(2):92-6. Pubmed PMID: 19639451.

[34]. Sert S, Bayirli GS. Evaluation of the root canal configurations of the mandibular and maxillary permanent teeth by gender in the Turkish population. J Endod. 2004 Jun;30(6):391-8. Pubmed PMID: 15167464.

[35]. Siddique R, Sureshbabu NM, Somasundaram J, Jacob B, Selvam D. Qualitative and quantitative analysis of precipitate formation following interaction of chlorhexidine with sodium hypochlorite, neem, and tulsi. J Conserv Dent. 2019 Jan-Feb;22(1):40-47. Pubmed PMID: 30820081.

[36]. Skidmore AE, Bjorndal AM. Root canal morphology of the human mandibular first molar. Oral Surg Oral Med Oral Pathol. 1971 Nov;32(5):778-84. Pubmed PMID: 5286234.

[37]. Song JS, Choi HJ, Jung IY, Jung HS, Kim SO. The prevalence and morphologic classification of distolingual roots in the mandibular molars in a Korean population. J Endod. 2010 Apr;36(4):653-7. Pubmed PMID: 20307739.

[38]. Stropko JJ. Canal morphology of maxillary molars: clinical observations of canal configurations. J Endod. 1999 Jun;25(6):446-50. Pubmed PMID: 10530248 .

[39]. Teja KV, Ramesh S. Shape optimal and clean more. Saudi Endodontic Journal. 2019 Sep 1;9(3):235.

[40]. Teja KV, Ramesh S, Priya V. Regulation of matrix metalloproteinase-3 gene expression in inflammation: A molecular study. J Conserv Dent. 2018 Nov- 
Dec;21(6):592-596. Pubmed PMID: 30546201.

[41]. 'Variations in root canal treatments' (2016) Dental Abstracts, pp. 74-76. doi: 10.1016/j.denabs.2015.08.024.

[42]. Vertucci FJ, Anthony RL. A scanning electron microscopic investigation of accessory foramina in the furcation and pulp chamber floor of molar teeth. Oral Surg Oral Med Oral Pathol. 1986 Sep;62(3):319-26. Pubmed PMID: 3462636.

[43]. Vertucci FJ, Haddix JE. Tooth morphology and access cavity preparation. InCohen's Pathways of the Pulp 2011 Jan 1 (pp. 136-222). Mosby.

[44]. Walker RT. Root form and canal anatomy of mandibular second molars in a southern Chinese population. J Endod. 1988 Jul;14(7):325-9. Pubmed
PMID: 3251992.

[45]. Wang Y, Zheng QH, Zhou XD, Tang L, Wang Q, Zheng GN, et al. Evaluation of the root and canal morphology of mandibular first permanent molars in a western Chinese population by cone-beam computed tomography. J Endod. 2010 Nov;36(11):1786-9. Pubmed PMID: 20951288.

[46]. Zheng QH, Wang Y, Zhou XD, Wang Q, Zheng GN, Huang DM. A cone-beam computed tomography study of maxillary first permanent molar root and canal morphology in a Chinese population. J Endod. 2010 Sep;36(9):1480-4. Pubmed PMID: 20728713. 